\title{
PROTON EXCHANGE MEMBRANE FUEL CELL WITH ENHANCED DURABILITY USING FLUORINATED CARBON AS ELECTROCATALYST
}

\author{
Yasser Ahmad ${ }^{(1)(2)}$, Katia Guérin ${ }^{(1)(2)}$, Laetitia Dubau ${ }^{(3)(4)}$, Marian Chatenet ${ }^{(3)}{ }^{(4)}$, Sandrine Berthon-Fabry $^{(5)}$ \\ (1) Université Clermont Auvergne, Université Blaise Pascal, Institut de Chimie de Clermont-Ferrand, BP 10448, F- \\ 63000 CLERMONT-FERRAND, France,Diane.Delbegue@univ-bpclermont.fr

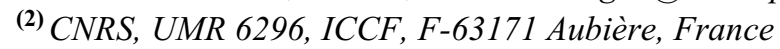 \\ (3) Univ. Grenoble Alpes, LEPMI, F-38000 Grenoble, France \\ (4) CNRS, LEPMI, F-38000 Grenoble, France \\ ${ }^{(5)}$ MINES ParisTech, PSL Research University PERSEE - Centre procédés, énergies renouvelables et systèmes \\ énergétiques, CS 10207 rue Claude Daunesse F-06904 Sophia Antipolis Cedex, France
}

\begin{abstract}
This study evaluates the fluorination of a carbon aerogel and its effects on the durability of the resulting electrocatalyst for Proton Exchange Membrane Fuel Cell (PEMFC). Fluorine has been introduced before or after platinum deposition. The different electrocatalysts are physico-chemically and electrochemically characterized, and the results discussed by comparison with commercial $\mathrm{Pt} / \mathrm{XC} 72$ from E-Tek. The results demonstrate that the level of fluorination of the carbon aerogel can be controlled. The fluorination modifies the texture of the carbons by increasing the pore size and decreasing the specific surface area, but the textures remain appropriate for PEMFC applications. Two fluorination sites are observed, leading to both high covalent C-F bond and weakened ones, the quantity of which depends on whether the treatment is done before or after platinum deposition. The order of the different treatments is very important. The presence of platinum contributes to the fluorination mechanism, but leads to amorphous platinum rather inactive towards the Oxygen Reduction Reaction. Finally, a better durability was demonstrated for the fluorinated then platinized catalyst compared both to the same but not fluorinated catalyst and to the reference commercial material (based on the loss of the electrochemical real surface area after accelerated stress tests).
\end{abstract}

\section{RESULTS AND DISCUSSION}

To minimize the corrosion of the catalyst support, several approaches have been tested. Graphitizing carbons improves their electronic conductivity and corrosion resistance [1-3]. Coatings with conductive polymers have also been studied [4], because of their high surface area, low ohmic resistance and stability, but the apparent electronic conductivity of the composite material often decreases during the catalyst deposition because it becomes disconnected electronically. Metal oxides, such as tin and indium oxide (ITO), $\mathrm{TiO}_{\mathrm{x}}, \mathrm{SnO}_{2}, \mathrm{WO}_{\mathrm{x}}, \mathrm{IrO}_{2}$, and carbides, such as $\mathrm{WC}$ and $\mathrm{W}_{2} \mathrm{C}$, have also been proposed as promising durable catalyst supports $[5,6]$, and to overcome the unsufficient electronic conductivity of the metal oxide, doping has been used $[7,8]$. Some researchers investigated $\mathrm{TiO}_{2} /$ carbon composites $[9,10]$ and showed that mixing carbon and $\mathrm{TiO}_{2}$ is beneficial to the electrocatalyst durability. Nevertheless, none of these solutions are completely satisfactory on the field.

In this research, the surface chemistry of the carbon aerogel CA was modified using a controlled fluorination. In order to limit the corrosion due to the oxidation of the carbon by its own oxygen content at its surface and the effect of the water environment, some of the dangling bonds were saturated with fluorine. So far, few fluorine-doped carbons (of the carbon blacks or template mesoporous carbon families) have been used as catalysts for their activity in alkaline medium [11,12] or in acidic media [13]. Because a high specific surface area of the carbon support is important for an optimized dispersion of platinum nanoparticle, and an adapted porosity is necessary to limit the mass transport losses, the study has been done on a carbon aerogel substrate, which possesses these 2 advantages [14]. In this work fluorinated and platinized carbon aerogels were synthesized and characterized as oxygen reduction reaction (ORR) electrocatalyst in acidic media, and their durability in PEMFC conditions was evaluated by accelerated stress tests performed in four-electrode cell. The results are discussed and compared to a benchmark electrocatalyst material (commercial $\mathrm{Pt} / \mathrm{XC} 72$, from ETek).

The bulk density of the monolithic pristine CA, determined is pbulk $=0.145 \pm 0.002$ g.cm-3. The texture of the CA materials, analyzed by nitrogen adsorption desorption, shows in any case a type IV curve with a H1 hysteresis loops in the IUPAC classification suggesting that the pristine and the modified materials are mainly mesoporous. However, the various treatments (insertion of platinum nanoparticles or fluorination) modify the texture within this "mesoporous range" (Table 1). The modification of the texture is different according to the treatment. 
Concerning the fluorination, the tendencies observed are the same on the CA or on the Pt-CA: the specific surface area decreases in both cases, all types of pore being modified. The total porous volume (determined by single point at $P / P^{\circ}=0.98$ ) increases owing to the increase of the macroporous volume, because the micropore and mesopore volumes both decrease. The limitation of the smallest pores leads to a decrease of the specific surface area of the material. This modification of the carbon texture during the fluorination (even if the level is low) could be compared to a strong activation phenomenon with the probable formation of gaseous $\mathrm{CF}_{4}$ or $\mathrm{C}_{2} \mathrm{~F}_{6}$.

\begin{tabular}{|c|c|c|c|c|c|}
\hline Sample & $\begin{array}{c}S_{\text {BET }^{\mathrm{a}}} \\
\left(\mathrm{m}^{2} \mathrm{~g}^{-1}\right) \\
\pm 5\end{array}$ & $\begin{array}{c}V_{\text {mic }} \\
\left(\mathrm{cm}^{3} \mathrm{~g}^{-1}\right) \\
\pm 0.004\end{array}$ & $\begin{array}{c}V_{\text {meso }} \\
(2-7.5 \mathrm{~nm}) \\
\left(\mathrm{cm}^{3} \mathrm{~g}^{-1}\right) \\
\pm 0.05\end{array}$ & $\begin{array}{c}V_{\text {meso }} \\
(2-50 \mathrm{~nm}) \\
\left(\mathrm{cm}^{3} \mathrm{~g}^{-1}\right) \\
\pm 0.05\end{array}$ & $\begin{array}{c}\mathrm{Vt}, \\
\left(\mathrm{cm}^{3} \mathrm{~g}^{-1}\right) \\
\pm 0.1\end{array}$ \\
\hline CA & 610 & 0.257 & 0.07 & 0.28 & 4.0 \\
\hline F-CA & 393 & 0.142 & 0.02 & 0.17 & 4.7 \\
\hline Pt-CA & 414 & 0.190 & 0.03 & 0.23 & 2.0 \\
\hline Pt/F-CA & 333 & 0.132 & 0.02 & 0.20 & 4.0 \\
\hline F/Pt-CA & 294 & 0.093 & 0.02 & 0.18 & 3.4 \\
\hline
\end{tabular}

Table 1. Textural characterizations for the various materials owing to $\mathrm{N} 2$ isotherms. SBET : specific surface area, Vmic : micropore volume $(<2 \mathrm{~nm})$, Vmeso : mesopore volume (width between 2 and 7.5 $\mathrm{nm}$ ), Vmeso : mesopore volume (width between 2 and $50 \mathrm{~nm}), \mathrm{Vt}$ : Total pore volume.

On the platinized material, the fluorination produces $\mathrm{PtF}_{6}$ gas [35] which can be able to open small porosity blocked by the platinum nanoparticles. -On the contrary, during the platinum deposition (on CA or on F-CA), the accessible volume decreases; this effect probably results from the fact that platinum nanoparticles sit (are stabilized) preferentially at the mouth of the small pores, thereby closing the corresponding porosity. The decreasing of the small pore volume naturally leads to a decrease of the specific surface area. This effect is more important in the non-fluorinated sample; indeed, the fluorination destroys the small pores, which are the main promoter of the specific surface area. Now, whatever the treatment, the specific surface area of the sample remains interesting in terms of value $\left(S_{\mathrm{BET}}>294\right.$ $\left.\mathrm{m}^{2} \mathrm{~g}^{-1}\right)$ and isotherm shape for use as PEMFC electrocatalyst and the pore size distribution is in accordance with the necessity of the water management: few micropores, few small mesopores $(<5 \mathrm{~nm})$ and a balance of the porosity between mesopores and TGA experiments show that the pristine CA material is stable in air up to $450^{\circ} \mathrm{C}$. At higher temperature, the carbon burns with the oxygen into $\mathrm{CO}_{2}$ (and $\mathrm{CO}$ ). All the treatments modify the thermal stability of the resultant material and the decomposition temperature of the oxidation of the non-fluorinated carbon parts $\left(T_{\mathrm{C}}\right.$ value) deceases with the number of treatment, whatever the order of the treatments. From ambient temperature to $150^{\circ} \mathrm{C}$, the mass lost is attributed to the elimination of the atmospheric water absorbed on the high specific surface areas carbons. F/Pt-CA is the less sensitive material to moisture. Above $220^{\circ} \mathrm{C}$, the platinum nanoparticles catalyze the degradation of the carbon in the air, as it can be seen on Pt-CA curve. On F-CA, the $\mathrm{C}-\mathrm{F}$ bonds formed are not removed until $170^{\circ} \mathrm{C}$, which confirms their high stability. For higher temperatures of thermal analysis, the C-F bonds are broken, and finally total defluorination is reached at $325^{\circ} \mathrm{C}$. The weight loss between $170^{\circ} \mathrm{C}$ and $347^{\circ} \mathrm{C}$ confirms the initial fluorination level (25 wt.\%) resulting of the fluorination by $\mathrm{XeF} 2$ of $\mathrm{CA}$ observed by weighting the sample before and after fluorination. For the platinized and fluorinated samples, the decomposition mechanism is more complex (and different according to the order of the treatment) due to the interaction between platinum (see $T_{\mathrm{C}-\mathrm{F}}$ ), fluorine, carbon and the different compounds produced during the degradation. A weak bond leads to the liberation of atomic fluorine and a strong one to the formation of $\mathrm{C}_{2} \mathrm{~F}_{4}$ and $\mathrm{CF}_{2}$ [36]. On the Pt/F-CA, defluorination begins at lower temperature and the weight loss is faster. On the F/Pt-CA, the behaviour is quite different. The differences could be linked to the type of bond rupture and to the reactivity of the platinum with the atomic fluorine formed during the decomposition, leading to the creation of volatile $\mathrm{PtF}_{6}$. The lack of crystallinity of the platinum in this sample also impacts the reactivity. The lower remaining weight at $600^{\circ} \mathrm{C}$ on the $\mathrm{Pt} / \mathrm{F}-\mathrm{CA}$ and $\mathrm{F} / \mathrm{Pt}-\mathrm{CA}$ samples compared to $\mathrm{Pt}-\mathrm{CA}$ one is consistent to this hypothesis.

The IR reveals two fluorination sites and explains the different behaviours of the samples. For all the fluorinated samples, the IR spectra show both highly covalent C-F bonds for wavenumber close to $1200 \mathrm{~cm}^{-1}$, together with weakened C-F bonds $\left(1100 \mathrm{~cm}^{1}\right)$. With platinum, new peaks appear between 600 and $750 \mathrm{~cm}^{-1}$. The F/Pt-CA leads to the same behaviour between the weakly and the highly covalent bonds, with higher quantity of weak bonds; a new peak appears at $600 \mathrm{~cm}^{-1}$, which could be attributed to a link between the platinum and the fluorine. This link could explain the higher degradation temperature observed in TGA compared to F-CA. The presence of platinum contributes to the fluorination mechanism (higher fluorine loading) and limits the formation of highly covalent bonds, which is a priori a drawback; this will be discussed later. The $\mathrm{Pt} / \mathrm{F}-\mathrm{CA}$ spectrum is slightly different from the F-CA spectrum. The process leading to the platinum insertion (insertion of the sample in a water-in-oil solution, $\mathrm{NaBH}_{4}$ reduction and washing with acetone, ethanol and MilliQ water) modifies the proportion between the highly and the weakly covalent C-F bonds. A part of the 
weak bonds could be involved with platinum. A peak at $750 \mathrm{~cm}^{-1}$ appears on $\mathrm{Pt} / \mathrm{F}-\mathrm{CA}$, while the one at $700 \mathrm{~cm}^{-1}$ is not observed anymore. This difference can be also attributed to a weak link between the platinum and the fluorine and also explains the different thermal behaviour of Pt/F-CA. Similar spectra are observed for $\mathrm{CA}$ and Pt-CA samples, confirming that no covalent bond exists between the carbon and the platinum.

By XRD it is possible to see the impact or the various treatments on the platinum particles size and their crystallinity. The mean crystallite size $\left(\bar{d}_{X R D}\right)$ was calculated from the Debye-Scherrer equation. The platinum particle sizes are comparable after the deposition on fluorinated or not CA sample. When the fluorination is done on the platinized sample, the platinum particles become essentially amorphous, as evidenced by the absence of diffraction peak.

The TEM micrographs confirm these values and permits to see the repartition of the particles at the CA or F-CA surface. For Pt-CA (Figure ), the platinum nanoparticles are quite well dispersed on the surface of the CA (around $5 \mathrm{~nm}$ and $10 \mathrm{~nm}$ ) and agglomerates can be occasionally observed (less than $20 \mathrm{~nm}$ ). On the contrary, for $\mathrm{Pt} / \mathrm{F}-\mathrm{CA}$, nearly all the $\mathrm{Pt}$ deposit is constituted of agglomerates of $c a$. 3-8 nm-sized crystallites (Figure 2). It appears that the Pt deposit is not interacting enough with the F-CA substrate to enable sufficient dispersion. On the F/Pt-CA electrocatalyst (Figure 3), the platinum nanoparticles are neither well defined nor well distributed on the carbon surface, on the contrary to the Pt-CA. The fluorination of the Pt-CA sample induces large modifications of the platinum texture and chemistry. Platinum nanoparticles of about $3 \mathrm{~nm}$ in size are observed and well distributed over the carbon substrate.

These different materials (with various texture, chemistry and quality of the platinum nanoparticles) have been characterized electrochemically in order to investigate the impact of fluorination treatment on the Oxygen Reduction Reaction (ORR) activity and stability.

The base voltammograms (Figure $10 \mathrm{~A}$ ) exhibit the classical $\mathrm{H}_{\mathrm{UPD}}$ behavior observed on platinum catalyst between 0.05 and $0.4 \mathrm{~V} v s$. RHE. Interestingly, all the catalyst supported on carbon aerogel show a very important double layer charge contribution, whether fluorinated or not. This typical behavior is linked to the wettability properties of the CA as well as the chemistry of its surface. It is also important to take in mind that the carbon support of our reference catalyst (Vulcan XC 72) has a lower specific surface area (around $250 \mathrm{~m}^{2} \mathrm{~g}^{-1}$ ) than the aerogel carbon studied here.

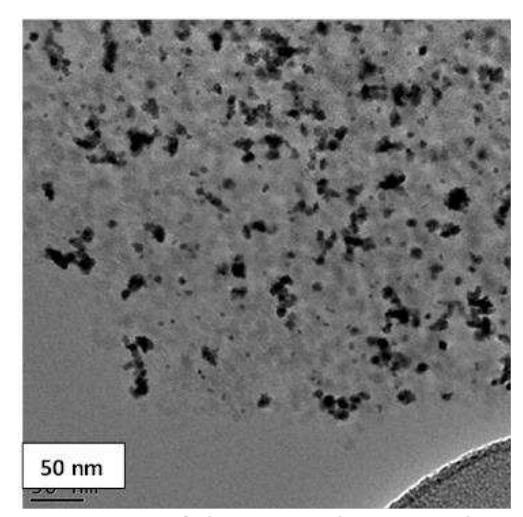

Figure 1. TEM pictures of the Pt-CA electrocatalyst.

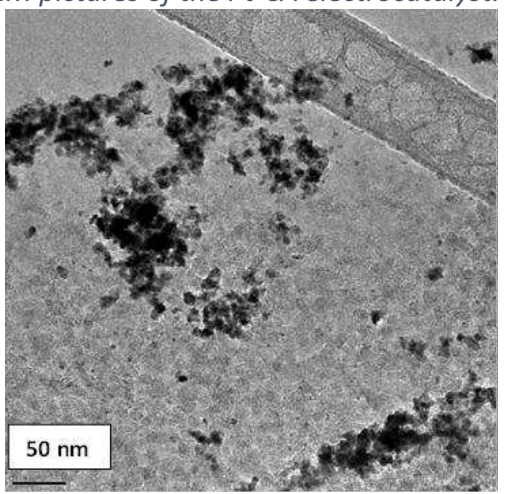

Figure 2. TEM pictures of Pt/F-CA electrocatalyst.

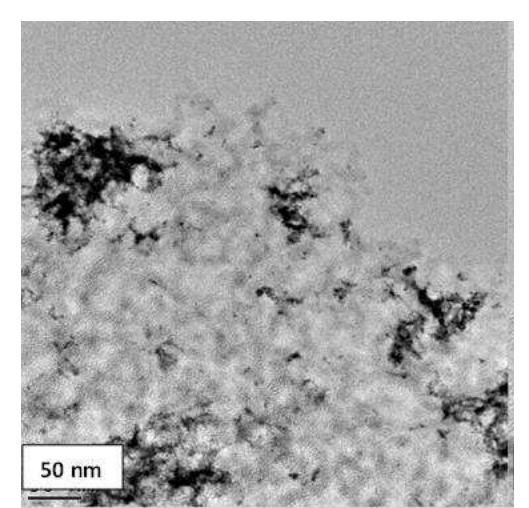

Figure 3. TEM pictures of F/Pt-CA electrocatalyst

CO stripping voltammograms are in agreement with the TEM observations of the different catalyst. The reference material shows a single peak which is the fingerprint of a very well-dispersed catalyst, as evidenced in the representative TEM images. In contrast, the $\mathrm{CO}$ stripping peaks performed on the electrocatalysts supported on the CA samples are larger and clearly present several contributions. In addition to the contribution corresponding to isolated particles, others contributions at lower potential sign the presence of agglomerated particles, since $\mathrm{CO}$ is more easily oxidized on the grain boundaries present between two aggregated particles .

The Tafel plots of the mass-transport-corrected kinetic current for Pt/CA, Pt/F-CA, F/Pt-CA electrodes and the 
reference $\mathrm{Pt} / \mathrm{C} 20 \%$ (E-Tek) material show that the specific activity measured at 0.85 and $0.90 \mathrm{~V}$ vs. RHE are summarized in Table 5. Pt/CA and $\mathrm{Pt} / \mathrm{F}-\mathrm{CA}$ are the most active electrocatalysts for the ORR and their specific activities are three times superior to the activity of the reference material at $0.90 \mathrm{~V}$ vs. RHE. It is well known that ORR is a structure-sensitive reaction and in that respect, platinum particle size plays a major role. The lower particle size presents a larger fraction of lowcoordinated sites on their surface which strongly adsorb ORR intermediates thus impacting negatively the activity $[38,40]$. It is therefore not surprising to obtain a higher activity in the case of the CA-supported electrocatalysts, owing to their larger Pt particles size [40]. According to the results derived from the XRD analysis (Table 2), the particle size of the reference material $(2.3 \mathrm{~nm})$ is well below the values obtained for the $\mathrm{Pt} / \mathrm{CA}$ and $\mathrm{Pt} / \mathrm{F}-\mathrm{CA}$ catalyst (around $4 \mathrm{~nm}$ ). It is also interesting to notice that the fluorination treatment made initially (before the platinum deposit) does not modify significantly the ORR activity.

In contrast, when the fluorination has been made after the Pt deposition, the ORR activity is very low; this result is probably due to the fact that the postfluorination treatment destroys the crystallinity of the $\mathrm{Pt}$ particles as shown in the XRD pattern in Figure 5.

\begin{tabular}{|c|c|c|}
\hline \multirow{2}{*}{ Electrode } & \multicolumn{2}{|c|}{$\mathrm{SA} / \mu \mathrm{cm}^{-2} \mathrm{Pt}$} \\
\cline { 2 - 3 } & $@ 0.85 \mathrm{~V}$ & @ $0.9 \mathrm{~V}$ \\
\hline Pt-CA & 250 & 59 \\
\hline $\mathrm{Pt} / \mathrm{F}-\mathrm{CA}$ & 212 & 55 \\
\hline $\mathrm{F} / \mathrm{Pt}-\mathrm{CA}$ & 71 & 16 \\
\hline $\mathrm{Pt} / \mathrm{XC72} \mathrm{E}-\mathrm{Tek}$ & 103 & 25 \\
\hline
\end{tabular}

Table 2. ORR kinetic parameters for $\mathrm{Pt} / \mathrm{CA}, \mathrm{Pt} / \mathrm{F}-\mathrm{CA}$ and F/Pt-CA electrodes and the reference $\mathrm{Pt} / \mathrm{C} 20 \%$ (ETek) determined in O2-saturated 0.1 M H2SO4; sweep rate $0.002 \mathrm{~V} \mathrm{~s}-1$; rotation rate $1600 \mathrm{rpm}$, positive-going potential sweep from 0.4 to $1 \mathrm{~V}$ vs. RHE; $\mathrm{T}=25 \pm 1^{\circ} \mathrm{C}$.

Accelerated stress tests (AST) were performed to investigate the robustness of the fluorinated $\mathrm{Pt}$ electrocatalyst and to get some insights into the role played by carbon-fluoride functionalization on the resistance towards carbon corrosion and consequent particle detachment. The aging procedure consisted of 5000 potential cycles between $0.60 \mathrm{~V} v$ s. RHE and 1.05 $\mathrm{V} v s$. RHE at a sweep rate $v=0.05 \mathrm{~V} \mathrm{~s}^{-1}$ in $0.1 \mathrm{M}$ $\mathrm{H}_{2} \mathrm{SO}_{4}$ and $T=298 \mathrm{~K}$ (liquid electrolyte). Such experimental conditions simulate the typical potential range experienced by a cathode material during PEMFC operation (i.e. at high and low current density, during idling and open circuit conditions). Different organizations such as the American Department of Energy (DoE) and the Fuel Cell Commercialization Conference of Japan (FCCJ) have their own AST protocols. In the "Electrocatalyst Cycle and Metrics" test from the American DOE, a triangle sweep cycle between 0.6 and $1.0 \mathrm{~V} v s$. RHE is used to investigate the stability of the metal nanoparticles. In the Japanese FCCJ procedure, start/stop cycles are mimicked by a triangular wave potential cycle between 1.0 and $1.5 \mathrm{~V}$ vs. RHE, and load cycles by a rectangular wave potential cycle between 0.6 and $1.0 \mathrm{~V}$ vs. RHE. Since carbon is thermodynamically unstable at a PEMFC cathode $\left(E_{\mathrm{CO} 2 / \mathrm{C}}^{0}=0.207 \mathrm{~V}\right.$ vs. NHE at $\left.298 \mathrm{~K}\right)$ and its corrosion is further catalyzed by $\mathrm{Pt}$, the choice of the potential window $0.6-1.05 \mathrm{~V} v s$. RHE appears adequate to evaluate the materials durability in PEMFC conditions, and notably to study the robustness of the metal nanoparticles, which is directly correlated to the stability of the carbon support, as previously characterized in this potential window by IL-TEM or indirectly by the detachment/migration of the platinum crystallites. Furthermore, even in PEMFC, the corrosion is visible when the potential remains in this range. It is even more true that the carbon is amorphous and is supporting platinum.

The changes in the electrochemically active surface area (ECSA) were monitored via $\mathrm{CO}_{\mathrm{ad}}$ stripping coulometry. The results, shown in Figure 4 demonstrate the better durability of the fluorinated catalyst compared to nonfluorinated catalyst, but also compared to the reference material. Here again, the particle size must be taken into account. The smallest particles are more prone to dissolve and redeposit (e.g. via Ostwald ripening), leading to larger crystallites and thus inducing larger ECSA losses upon ageing. The promising result of this study comes from the comparison of $\mathrm{Pt} / \mathrm{CA}$ and $\mathrm{Pt} / \mathrm{F}$ $\mathrm{CA}$, which directly allows checking the impact of fluorination on the durability (the particle sizes of these samples are essentially identical). Fluorination induces a lower ECSA decrease upon cycling (10.5\% vs. $17 \%$ ECSA loss) when comparing the fluorinated with nonfluorinated electrocatalyst. Unfortunately, it was not possible to quantify the degree of fluorination after the AST due to the very low amount of catalyst available on the working electrode $(30 \mu \mathrm{g})$. At the light of this study, it is not possible to conclude on the origin of this spectacular result. Two hypotheses can be considered, a better resistance to corrosion and/or an optimization of the anchoring of $\mathrm{Pt}$ nanoparticles on the fluorinated carbon support. Concerning this last point, we have to keep in mind the obvious interaction between the carbon, the fluorine and the platinum. The presence of the platinum on fluorinated carbon aerogel modifies the two different bonds between the carbon and the fluorine [14] and the fluorination on the platinized carbon, not only modifies the both C-F interactions but leads to amorphous platinum. 


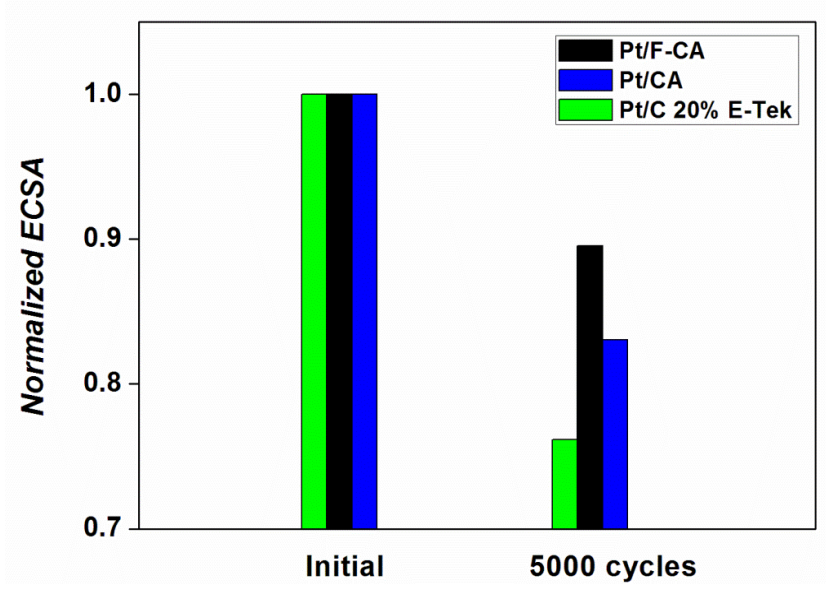

Figure 4. Comparison of the electrochemical surface area (ECSA) estimated by CO stripping coulometry before and after an AST consisting of 5000 potential cycles between $0.60 \mathrm{~V}$ vs. RHE and $1.05 \mathrm{~V}$ vs. RHE at a sweep rate $\mathrm{V}=0.05 \mathrm{~V} \mathrm{~s}-1$ in $0.1 \mathrm{M} \mathrm{H} 2 \mathrm{SO} 4$ and $\mathrm{T}=298$ $\mathrm{K}$.

\section{References}

[1] D. Zhai, H. Du, B. Li, Y. Zhu, F. Kang. Porous graphitic carbons prepared by combining chemical activation with catalytic graphitization Carbon 49 (2011) 725-729

[2] H. Jin, H. Zhang, Y. Ma, T. Xua, H. Zhong, M.J. Wang. Stable support based on highly graphitic carbon xerogel for proton exchange membrane fuel cells. Power Sources 195 (2010) 6323-6328

[3] F. Alcaide, G. Álvarez, O. Miguel, M.J. Lázaro. Stability of carbon nanofibers as catalyst supports for PEMFC. Book of Abstracts. $2^{\text {nd }}$ CARISMA International Conference on Progress in MEA 2010, La Grande Motte (France), 2010 p. 151

[4] G. Inzelt, M. Pineri, J.W. Schultze, M.A. Vorotyntsev. Electron and proton conducting polymers: recent developments and prospects Electrochim. Acta 45 (2000) 2403-2421.

[5] E. Antolini, E. Gonzalez. Solid State Ionics. Ceramic materials as supports for low-temperature fuel cell catalysts. 180 (2009) 746-763

[6] S.Y. Huang, P. Ganesan, B.N. Popov. Titania supported platinum catalyst with high electrocatalytic activity and stability for polymer electrolyte membrane fuel cell. Applied Catalysis B: Environmental 102 (2011) 71-77

[7] I. Cerri, T. Nagami, B.E. Hayden, J.C. Davies. Durable electrocatalysts for PEMFC. Proceeding of the Fundamentals and Developments of Fuel Cell Conference, Grenoble (France), 2011 p 282-283

[8] K. Sasaki, F. Takasaki, Y. Shiratori, Z. Noda. Alternative electrocatalyst support materials for polymer electrolyte fuel cells : semiconducting oxides and carbon nanofibers. Proceedings of the 18th World Hydrogen Energy Conference (2010)

[9] L. Xiong, A. Manthiram. Synthesis and characterization of methanol tolerant $\mathrm{Pt} / \mathrm{TiOx} / \mathrm{C}$ nanocomposites for oxygen reduction in direct methanol fuel Cells, Electrochim. Acta 49 (2004) 4163-4170

[10] A. Bauer, C. Songa, A. Ignaszaka, R. Huia, J. Zhanga, L. Chevallier et al. Improved stability of mesoporous carbon fuel cell catalyst support through incorporation of TiO2. Electrochim. Acta 55 (2010) 8365-8370

[11] H. Wang, A. Kong, Mesoporous fluorine-doped carbon as efficient cathode material for oxygen reduction reaction, materials letters 136 (2014) 384-387 [12] X. Sun, Y. Zhang, P. Song, J. Pan, L. Zhuang, W. $\mathrm{Xu}, \mathrm{W}$. Xing, Fluorine-Doped Carbon Blacks: Highly Efficient Metal-Free Electrocatalysts for Oxygen Reduction Reaction ACS Catalysis 2013, 3, 17261729 [13] X. Sun, P. Song, T. Chen, J. Liu, W. Xu, Fluorinedoped BP 2000: highly efficient metal-free electrocatalysts for acidic oxygen reduction reaction with superlow H2O2 yield, Chem. Commun., 2013,49, 10296-10298

[14] M. Ouattara-Brigaudet, S. Berthon-Fabry, C. Beauger, M. Chatenet, N. Job, M. Sennour, P. Achard, Influence of the carbon texture of platinum/carbon aerogel electrocatalysts on their behavior in Proton Exchange Membrane Fuel Cell cathode, International Journal of Hydrogen Energy 37 (2012) 9742-9757 